\title{
EVALUASI IMPLEMENTASI PAJAK PROGRESIF TERHADAP KENDARAAN BERMOTOR DI KABUPATEN MINAHASA UTARA PROVINSI SULAWESI UTARA
}

\author{
Mandang Adiputra ${ }^{1}$, Herman Karamoy ${ }^{2}$, Sonny Pangerapan ${ }^{3}$ \\ ${ }^{1,2,3}$ Fakultas Ekonomi dan Bisnis, Jurusan Akuntansi, Universitas Sam Ratulangi, Jl. Kampus Bahu, Manado, \\ 95115, Indonesia \\ E-mail : mandangrul@yahoo.co.id
}

\begin{abstract}
Motor vehicle tax is a potential tax in local revenue. Progressive tax on motor vehicles is valid from January 2012 in North Sulawesi based on the implementation of the Provincial Regulation No. 7 of 2011 on Regional Taxes. The purpose of this study is to know the implementation of progressive tax on motor vehicles in North Minahasa District and to determine the inhibiting factor appear in the implementation of progressive tax implementation. The method used in this research is descriptive method that is by collecting data from the results of the research and then analyzing and drawing conclusions from the research. The results obtained that the implementation of progressive tax on motor vehicles in North Minahasa District has been implemented based on existing regulations and taxpayers also have to pay motor vehicle tax based on prevailing rates. However, there are inhibiting factors in the implementation of progressive tax, namely the factor of officers who carry out data collection because often vehicle owners are not in place, facilities and infrastructure factors because not all taxpayers can pay during SAMSAT office hours, the factor of SAMSAT are input errors vehicle owner data, and the factor of the people who are still not aware of the progressive tax rate.
\end{abstract}

Keywords : Motor Vihecle Tax, Progressive Tax, Implementation.

\section{PENDAHULUAN}

Berkembangnya ilmu pengetahuan dan teknologi dalam era modern ini telah berdampak positif terhadap kehidupan manusia saat ini, salah satunya dapat dirasakan oleh masyarakat adalah kemajuan di bidang transportasi. Kendaraan bermotor menjadi pilihan dalam memenuhi kebutuhan sebagai penunjang kelengkapan hidup dan perekonomian masyarakat, karena dapat mempermudah akses dalam melakukan kegiatan sehari-hari. Selain manfaat dan kegunaannya dapat juga dijadikan sebagai simbol status sosial bagi pemiliknya.

Berlakunya Undang-Undang No. 28 Tahun 2009 tentang Pajak Daerah dan Retribusi Daerah, pemerintah berupaya untuk meningkatkan pajak kendaraan bermotor dan mengendalikan jumlah kendaraan bermotor dengan tarif Pajak Kendaraan Bermotor dikenakan secara progresif, dengan jumlah pengendara roda dua dan roda empat secara massal penggunaan jalan raya yang merupakan barang publik mempunyai beban biaya bertambah, baik secara langsung maupun tidak langsung, sehingga pemerintah dapat mengendalikan jumlah kendaraan bermotor tanpa mengurangi fungsi Pajak Kendaraan Bermotor sebagai salah satu sumber penerimaan pajak daerah. Pajak Kendaraan Bermotor ialah pajak terhadap orang yang mempunyai atau menguasai kendaraan bermotor, yaitu kendaraan roda dua atau lebih yang digunakan di jalan yang digerakan dengan motor yang dapat mengubah sumber daya energi menjadi tenaga gerak.

Salah satu upaya yang dilakukan pemerintah untuk meningkatkan otonomi daerah adalah dengan mengoptimalkan pendapatan daerah yaitu mengenakan tarif yang lebih tinggi. Pajak progresif merupakan pajak yang pemungutannya menaikkan tarif pajak yang terutang 
dengan bertambahnya objek pajak. Peraturan perpajakan yang ada di Indonesia salah satu pajak yang diterapkan dengan sistem tarif progresif yaitu pajak kendaraan bermotor.

\section{TINJAUAN PUSTAKA}

Konsep Akuntansi. Definisi akuntansi menurut Pontoh (2013:2), yaitu "Akuntansi adalah sebuah sistem informasi yang dirancang oleh sebuah organisasi untuk mengidentifikasi (analisis, mencatat, dan meringkas) aktivitas-aktivitas yang mempengaruhi kondisi dan kinerja keuangannya, kemudian mengkomunikasikan hasilnya kepada para pengambil keputusan, baik dari internal maupun eksternal organisasi". Sedangkan menurut Sarundayang (2018:273-274) Akuntansi adalah pencatatan, pengglolongan, pengiktisaran, dan pelaporan atas suatu kejadian dengan cara sedemikian rupa, yang tersistematis dari isi, dan berdasarkan standar yang diakui umum. Oleh karena itu, entitas yang bersangkutan bisa melihat posisi keuangan perusahaan. Sehingga bisa mengambil kesimpulan atau pilihan atas aktivitas ekonomi perusahaan.

Konsep Akuntansi Pajak. Menurut Londorang (2014:1628) menyatakan akuntansi pajak ialah akuntansi yang berhubungan dengan kalkulasi perpajakan yang bertumpu pada aturan perpajakan beserta metode dalam penerapannya. Sedangkan definisi akuntansi pajak yang dikutip dari Jurnal Riset Akuntansi Going Concern Dunggio (2017:141) Akuntansi pajak menggambarkan bagian dari akuntansi yang muncul melalui keahlian tertentu khususnya dalam bidang perpajakan.

\section{Konsep Pajak}

1. Pengertian Pajak. Pajak menurut Mardiasmo (2018:3), "Pajak adalah iuran rakyat kepada negara berdasarkan undang-undang (yang dapat dipaksakan) dengan tidak dapat jasa timbal balik (konsentrasi), yang langsung dapat ditunjukkan dan yang digunakan untuk membayar pengeluaran umum". Sedangkan definisi pajak yang dikutip dalam Jurnal Riset Akuntansi Going Concern Korengkeng (2017:211-212) Pajak adalah prestasi yang dipaksakan sepihak oleh dan terutang kepada pengusaha menurut norma-norma yang ditetapkannya secara umum, tanpa adanya kontraprestasi, dan semata-mata digunakan untuk menutup pengeluaran umum.

2. Fungsi Pajak. Resmi (2014:3) terdapat dua fungsi pajak yaitu sebagai berikut : (1) fungsi Budgetair (Sumber Keuangan Negara); dan (2) fungsi Regulerend (Pengatur).

3. Syarat Pemungutan Pajak. Menurut Mardiasmo (2018:4) syarat pemungutan pajak yakni : (1) harus adil; (2) berdasarkan undang-undang; (3) tidak berkaitan dengan unsur ekonomi; (4) tidak melebihi biaya pungut; dan (5) sederhana.

4. Teori Pemungutan Pajak. Menurut Mardiasmo (2018:5), teori-teori pemungutan pajak yaitu: (1) teori asuransi; (2) teori kepentingan; (3) teori daya pikul; (4) teori bakti; dan (5) teori asas daya beli.

5. Jenis-jenis Pajak. Menurut Resmi (2014:7) pajak dapat digolongkang sebagai berikut : (1) menurut golongan; (2) menurut sifatnya; dan (3) menurut lembaga pemungutan.

6. Cara Pemungutan Pajak. Menurut Mardiasmo (2018:8) ada 3 (tiga) cara dalam memungut pajak yaitu:

1. Stelsel Pajak: (a) nyata (riel stelsel); (b) anggapan (fictieve stelsel); dan (c) campuran.

2. Asas Pemungutan Pajak : (a) berdasarkan tempat tinggal; (b) berdasarkan sumber; dan (c) kebangsaan.

\section{Sistem Pemungutan Pajak}

- Official Assessment System. Besaran pajak yang harus dibayar oleh wajib pajak ditentukan oleh pemerintah.

- Self Assessment System. Wajib pajak sendiri yang menentukan besaran pajak yang harus dibayar. 
- Withholding System. Orang ketiga diberikan kuasa untuk memotong atau memungut pajak yang harus dibayarkan wajib pajak.

8. Hambatan Pemungutan Pajak. Mardiasmo (2018:10) ada 2 (dua) perlawanan pajak yakni: (1) Perlawanan Pasif; dan (2) Perlawanan Aktif, melalui (a) Tax avoidance, tindakan yang mengurangi nilai pajak tanpa melawan aturan; dan (b) Tax evasion, tindakan mengurangi nilai pajak dengan malawan aturan.

9. Tarif Pajak. Terdapat empat macam tarif pajak yang dikemukakan Mardiasmo (2018:11), yaitu : (1) tarif sebanding/proposional; (2) tarif tetap; (3) tarif progresif; dan (4) tarif degresif.

\section{Pajak Daerah}

1. Konsep Pajak Daerah. Menurut Undang-Undang Nomor 28 Tahun 2009 Tentang Pajak dan Retribusi Daerah, Pajak Daerah adalah, Iuran yang wajib disetor ke daerah oleh orang pribadi atau badan dengan tidak mendapatkan timbal balik langsung dan bisa dipaksakan berdasarkan peraturan perundang-undangan yang ada, yang digunakan untuk keperluan pemerintah daerah dan pembangunan daerah.

2. Jenis-Jenis Pajak Daerah. Pajak dari daerah terbagi atas dua berdasarkan UndangUndang Nomor 28 Tahun 2009 tentang Pajak Daerah \& Retribusi Daerah, yaitu pajak Provinsi dan Pajak Kota/Kabupaten. Pajak Provinsi terdiri 5 (lima) jenis pajak yang dipungut, salah satunya adalah Pajak Kendaraan Bermotor (PKB). Sedangkan untuk Kota/Kabupaten ada 11 (sebelas) jenis pajak yang dipungut.

Pajak Kendaraan Bermotor

1. Konsep Pajak Kendaraan Bermotor. Berdasarkan Undang-Undang Nomor 28 Tahun 2009 tentang Pajak Daerah \& Retribusi Daerah, Pajak Kendaraan Bermotor ialah pajak terhadap orang yang mempunyai atau menguasai kendaraan bermotor.

2. Objek Pajak Kendaraan Bermotor. Berdasarkan kebijakan Provinsi Sulawesi Utara Nomor 7 Tahun 2011 tentang Pajak Daerah, objek pajak kendaraan bermotor, ialah orang yang mempunyai atau menguasai kendaraan bermotor.

3. Subjek Pajak Kendaraan Bermotor. Berdasarkan Kebijakan Provinsi Sulawesi Utara Nomor 7 Tahun 2011 tentang Pajak Daerah, subjek pajak kendaraan bermotor, adalah orang pribadi, badan, pemerintah, pemerintah daerah, TNI dan Polri yang memiliki dan/atau menguasai Kendaraan Bermotor.

4. Wajib Pajak Kendaraan Bermotor. Berdasarkan Kebijakan Provinsi Sulawesi Utara Nomor 7 Tahun 2011 tentang Pajak Daerah Pasal 5 Wajib Pajak Kendaraan Bermotor, yaitu: (1) orang yang bersangkutan, yaitu sebagai pemilik sesuai dengan hak kepemilikannya; (2) orang atau badan yang memperoleh kuasa dari pemilik kendaraan bermotor; dan (3) ahli waris.

5. Dasar Pengenaan Pajak Kendaraan Bermotor. Berdasarkan Kebijakan Daerah Provinsi Sulawesi Utara Nomor 7 Tahun 2011 tentang Pajak Daerah, pengenaan pajak kendaraan bermotor merupakan hasil kali antara Nilai Jual Kendaraan Bermotor dengan Bobot yang merupakan tingkat batas toleransi suatu kendaraan.

6. Tarif Pajak Kendaraan Bermotor. Menurut Undang-Undang Nomor 28 Tahun 2009 tentang Pajak \& Retribusi Daerah, Pengenaan tarif untuk kendaraan bermotor yakni, 1\% (satu persen) dan maksimal 2\% (dua persen) bagi pengusaan untuk kendaraan pertama. Sedangkan untuk penguasaan berikutnya ditetapkan dari $2 \%$ (dua persen) dan maksimal 10\% (sepuluh persen).

7. Pajak Progresif. Pajak progresif merupakan pajak yang pemungutannya menaikkan tarif pajak yang terutang dengan bertambahnya objek pajak. Pajak progresif kendaraan bermotor adalah pajak yang dipungut bagi kendaraan pribadi baik roda dua dan roda empat dengan nama pemilik dan alamat tempat tinggal yang sama. 
Penelitian Terdahulu. Moningka (2017) dengan judul Analisis Pengenaan Tarif Pajak Progresif Pada Pajak Kendaraan Bermotor Berdasarkan The Four Maxims di Kabupaten Minahasa. Tujuan penelitian ini adalah untuk mengetahui bagaimana penerapan kenaikan dari tarif pajak atas kendaraan bermotor menurut The Four Maxims di Kabupaten Minahasa. Hasil penelitian ini menunjukkan pelaksanaan kenaikan dari tarif pajak atas kendaraan bermotor menurut The Four Maxims masih dianggap, relevan berdasarkan metode yang diajukan menurut Adam Smith. Nuzul (2015) dengan judul Analisis Penerapan Pajak Progresif Kendaraan Bermotor Dalam Rangka Meningkatkan Pendapatan Asli Daerah Pada Kantor Sistem Administrasi Manunggal Satu Atap (SAMSAT) Medan Selatan. Tujuan dari penelitian ini ialah, pencapaian target penerimaan pajak kendaraan bermotor dan menganalisa pajak progresif tahun 2013-2014. Hasil penelitian ini menunjukkan penerimaan pajak kendaraan bermotor di UPT Medan Selatan terus menunjukkan peningkatan setiap tahun, meskipun pada tahun 2013 dan 2014 tidak mencapai target yang telah ditentukan.

\section{METODE PENELITIAN}

Jenis Penelitian. Jenis penelitian yang digunakan dalam penelitian ini adalah deskriptif kualitatif sebagai acuan untuk mengetahui implementasi pajak progresif di Kabupaten Minahasa Utara. Pengkajian deskriptif ialah pengkajian yang mengarahkan peneliti membuat gambaran yang ada menjadi tersistematis berdasarkan keadaan yang ada di lapangan (Suryabrata, 2013:75).

Tempat dan Waktu Penelitian. Penelitian ini dilakukan pada Kantor BP2RD (Badan Pengelola Pajak dan Retribusi Daerah) Unit Pelaksana Teknis Badan (UPTB) Minahasa Utara yang bertempat di Jl. Raya Sukur Likupang, Airmadidi, Kabupaten Minahasa Utara, Sulawesi Utara. Waktu pelaksanaan penelitian diawali pada Bulan Mei s/d Bulan Juni 2018.

\section{Jenis, Sumber dan Metode Pengumpulan data}

1. Jenis Data. Jenis data yang digunakan dalam penelitian ini adalah menggunakan data kualitatif yang merupakan acuan untuk menelaah bagaimana implementasi pajak progresif terhadap kendaraan bermotor di Kabupaten Minahasa Utara pada Badan Pengelola Pajak dan Retribusi Daerah UPTB Minahasa Utara.

2. Sumber data. Sumber data yang digunakan adalah sumber data primer. Sumber data primer dalam penelitian ini adalah catatan hasil wawancara, rekapitulasi penerimaan pajak progresif, dan rekapitulasi penerimaan pajak di BP2RD Kabupaten Minahasa Utara.

3. Metode Pengumpulan Data. Metode pengumpulan data yang digunakan adalah: (1) observasi. Pengempulan bukti melalui pengamatan, pada saat terjadinya aktivitas seseorang, jalannya suatu mekanisme, dan kejadian disekitarnya; dan (2) wawancara. Peneliti mewawancarai langsung pihak-pihak yang terkait mengenai data yang diperlukan dalam hal ini Kepala Sub Bag. Tata Usaha, staff Bag. Sengketa Pajak, dan Kepala Kantor UPTB.

Metode Analisis. Dalam skripsi ini penulis menggunakan metode analisis yang mengacu pada metode deskriptif yakni menganalisis suatu aspek kemudian menarik kesimpulan (Sujarweni, 2014: 46). Penulis menguraikan data rekapitulasi penerimaan pajak progresif, dan rekapitulasi penerimaan pajak, serta hasil wawancara yang dilaksanakan pada BP2RD Kab. Minahasa Utara kemudian diolah oleh penulis sehingga dapat diambil kesimpulan secara sistematis. 


\section{HASIL PENELITIAN DAN PEMBAHASAN}

\subsection{Hasil Penelitian}

1. Implementasi Pajak Progresif Terhadap Kendaraan Bermotor di Kabupaten Minahasa Utara

Berdasarkan hasil wawancara yang dilakukan peneliti dengan kepala UPTB, kenaikan tarif pajak kendaraan bermotor(Tarif Progresif) mulai diberlakukan di Provinsi Sulawesi Utara sejak Januari 2012. Implementasi tarif pajak progresif ini didasari oleh Undang-Undang Nomor 28 Tahun 2009 tentang Pajak Daerah dan Retribusi Daerah, yang implementasinya berdasarkan Kebijakan Daerah Provinsi Sulawesi Utara Nomor 7 Tahun 2011 tentang Pajak Daerah. Kenaikan tarif pajak kendaraan ini berlaku untuk penguasaan yang melebihi dari satu unit. Kenaikan tarif pajak kendaraan ini berlaku untuk kendaraan roda 2 (dua) ke roda 2 (dua) dan kendaraan roda 4 (empat) ke roda 4 (empat) kecuali kendaraan jenis Dump Truck, Light Truck dan Pick Up.

2. Penentuan Urutan Pajak Progresif Kendaraan Bermotor

Penentuan tarif pajak progresif terhadap kendaraan bermotor ditetapkan menurut waktu registrasi kendaraan yang tersimpan dalam bank data. Sedangkan untuk kendaraan bekas penentuan urutannya berdasarkan tahun tertua kendaraan atau tahun ketika balik nama kendaraan bermotor terjadi.

\section{Penerimaan Pajak Daerah Kabupaten Minahasa Utara}

\section{Tabel 4.1}

Realisasi Penerimaan Pajak Daerah UPTD Minahasa Utara Tahun 2015, 2016, dan 2017

(dalam rupiah)

\begin{tabular}{|l|l|r|r|r|}
\hline $\begin{array}{c}\text { No } \\
.\end{array}$ & JENIS PENERIMAAN & $\begin{array}{c}\text { Realisasi Tahun } \\
2015\end{array}$ & $\begin{array}{c}\text { Realisasi Tahun } \\
2016\end{array}$ & $\begin{array}{c}\text { Realisasi Tahun } \\
2017\end{array}$ \\
\hline 1. & PKB & 22.415 .015 .500 & 24.557 .981 .710 & 27.747 .068 .346 \\
\hline 2. & BBN-KB & 25.666 .218 .000 & 26.500 .102 .500 & 32.311 .627 .600 \\
\hline 3. & PAP & 0 & 44.422 .716 & 22.076 .538 \\
\hline 4. & DENDA PKB & 1.519 .453 .000 & 651672.800 & 638.936 .300 \\
\hline 5. & DENDA BBN-KB & 96.047 .500 & 31.261 .500 & 0 \\
\hline 6. & PAJAK ALAT BERAT & 372.529 .000 & 192.984 .567 & 0 \\
\hline 7. & TUNTUTAN GANTI & 0 & 10.500 .00 & 0 \\
& RUGI DAERAH & & & \\
\hline
\end{tabular}

Sumber : BP2RD UPTB Minahasa Utara Tahun 2018

Tabel 4.1, menunjukkan realisasi penerimaan pajak kendaraan bermotor mengalami peningkatan yang cukup signifikan setiap tahunnya, di tahun 2015 sebesar Rp22.415.015.500,00 mengalami kenaikan di tahun 2016 menjadi Rp24.557.981.710,00 dan terus naik sampai tahun 2017 menjadi Rp27.747.068.346,00. Begitu pula dengan jenis penerimaan BBN-KB yang mengalami kenaikan setiap tahunnya. 
Tabel 4.2

Realisasi Penerimaan PKB Tahun Anggaran 2015, 2016, dan 2017

(dalam rupiah)

\begin{tabular}{|c|c|r|r|r|}
\hline \multirow{2}{*}{ No } & \multirow{2}{*}{ BULAN } & \multicolumn{2}{|c|}{ PENERIMAAN PAJAK KENDARAAN BERMOTOR } \\
\cline { 3 - 5 } & & Tahun 2015 & Tahun 2016 & \multirow{2}{*}{ Tahun 2017} \\
\hline 1 & JANUARI & 1.956 .745 .500 & 2.281 .948 .800 & 2.375 .587 .800 \\
\hline 2 & FEBRUARI & 1.676 .853 .300 & 1.783 .013 .500 & 1.991 .857 .800 \\
\hline 3 & MARET & 2.149 .454 .900 & 2.224 .276 .900 & 2.594 .190 .800 \\
\hline 4 & APRIL & 1.910 .034 .800 & 2.150 .023 .300 & 2.122 .860 .850 \\
\hline 5 & MEI & 1.830 .236 .600 & 2.321 .399 .000 & 2.293 .574 .000 \\
\hline 6 & JUNI & 2.001 .264 .500 & 2.072 .927 .500 & 1.813 .110 .200 \\
\hline 7 & JULI & 1.917 .853 .500 & 1.799 .849 .500 & 2.476 .228 .600 \\
\hline 8 & AGUSTUS & 1.898 .613 .900 & 2.113 .021 .000 & 2.362 .651 .800 \\
\hline 9 & SEPTEMBER & 2.047 .788 .000 & 2.054 .779 .500 & 2.060 .010 .260 \\
\hline 10 & OKTOBER & 2.146 .914 .000 & 2.119 .968 .800 & 2.822 .376 .461 \\
\hline 11 & NOVEMBER & 2.061 .488 .900 & 2.302 .932 .000 & 2.605 .480 .775 \\
\hline 12 & DESEMBER & 2.337 .220 .500 & 1.985 .514 .700 & 2.229 .139 .000 \\
\hline & JUMLAH & 23.934 .468 .400 & 25.209 .654 .500 & 27.747 .068 .346 \\
\hline
\end{tabular}

Sumber : BP2RD UPTB Minahasa Utara Tahun 2018

Gambar 4.1

Perbandingan Realisasi penerimaan Pajak Kendaraan Bermotor Tahun Anggaran 2015, 2016, \& 2017 UPTB Minahasa Utara

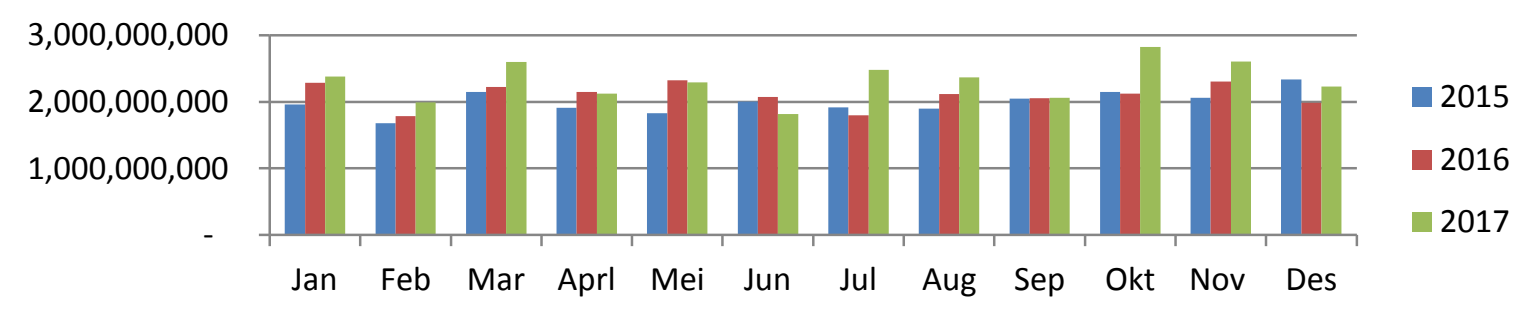

Sumber : BP2RD UPTB Minahasa Utara (Olahan Penulis)

Tabel 4.2 dan gambar 4.1 menunjukkan perbandingan penerimaan pajak kendaraan bermotor pada tahun 2015, 2016 dan 2017. Dapat dilihat dari penerimaan pajak kendaraan bermotor berjalan secara dinamis dan terus meningkat.

\subsection{Pembahasan}

1. Implementasi Pajak Progresif Terhadap Kendaraan Bermotor di Kabupaten Minahasa Utara

Berdasarkan hasil observasi peneliti, implementasi pajak progresif di Kabupaten Minahasa Utara telah menggunakan sistem komputerisasi yang terintegrasi di mana setiap data wajib pajak yang memiliki kendaraan akan tercatat di dalam database. Database ini merupakan basis data atau kumpulam informasi pemilik kendaraan yang disimpan secara sitematis sehingga dapat diperiksa menggunakan program komputer untuk memperoleh informasi dari basis data tersebut. Pada database menyimpan seluruh informasi yang dibutuhkan mengenai kendaraan bermotor di antaranya:

1. Jumlah kepemilikan kendaraan yang ada di satu wilayah tertentu baik itu kendaraan roda 2 (roda dua), roda 4 (roda empat), roda 6 (roda enam) dan seterusnya. 
2. Jumlah kendaraan yang menunggak (belum membayar pajak).

3. Jumlah kendaraan yang akan jatuh tempo pembayaran.

4. Wajib pajak yang dikenakan tarif progresif mulai dari roda 2 (roda dua) dan seterusnya.

5. Jumlah pemilik kendaraan yang datang membayar setiap harinya.

6. Data kendaraan baru.

7. Data kendaraan yang mutasi, baik mutasi masuk dan mutasi keluar.

8. Data Bea Balik Nama Kendaraan Bermotor.

Database ini menjadi dasar dalam hal administrasi yang dilakukan oleh kantor SAMSAT sehingga dapat mengidentifikasi setiap kendaraan bermotor dalam hal registrasi kendaraan dan untuk keperluan lainnya. Di dalam sistem juga sudah diisi dengan Koding yakni kode identifikasi kendaraan menurut jenis, tipe, merek, dan jumlah roda. Berdasarkan database dapat diketahui berapa Nilai Jual Kendaraan Bermotor (NJKB) dan jumlah penetapan pajak kendaraan bermotor. Untuk tarif pembayaran pajak progresif ditetapkan berdasarkan urutan kepemilikan kendaraan wajib pajak yang ada pada database sehingga dapat terlihat tarif dari tiap kendaraan wajib pajak yang akan membayar pajak kendaraan bermotor. Namun sering terjadi ketika wajib pajak sudah tidak memiliki/menguasi kendaraan bermotor namun di database masih tercatat sebagai nama wajib pajak sehingga wajib pajak harus membayar beban pajak yang sudah tidak dimilikinya. Untuk itu wajib pajak dapat malaporkan bahwa kendaraan telah dijual sehingga urutan dan tarif dari kendaraan dapat berubah. Pada saat melakukan pembayaran pajak kendaraan bermotor sistem akan terhubung dengan database kemudian sistem akan mengikuti databse yang ada dan menghitung dengan sendirinya berapa jumlah yang harus dibayarkan oleh wajib pajak.

2. Penetapan Urutan Kepemilikan Kendaraan Bermotor

Menurut hasil wawancara dengan kepala Unit Pelaksana Teknis Badan (UPTB), kenaikan tarif pajak kendaraan bermotor sudah ada sejak Bulan Januari 2011 namun pada waktu itu hanya bersifat sebagai sosialisasi. Pada Bulan September 2011 sampai Bulan Desember 2011, pemilik kendaraan diberikan keringanan dengan tidak membayar biaya administrasi untuk melakukan BBN-KB (Bea Balik Nama Kendraan Bermotor). Kantor Bersama SAMSAT Minahasa Utara melakukan hal tersebut untuk memberi kemudahan kepada pemilik kendaraan mengatur urutan kendaraannya dan sebagai cara untuk menaikan BBN-KB.

3. Faktor penghambat dalam Implementasi Pajak Progresif Terhadap Kendaraan Bermotor

1. Hambatan bagi pegawai yang bertugas melaksanakan pengidentifikasian kendaraan bermotor di lapangan. Waktu pegawai yang bertugas datang di kediaman pemilik kendaraan namum pemilik kendaraan tidak berada di tempat. Akibatnya pegawai yang bertugas mengambil jalan lain yaitu menanyakan status kendaraan tersebut kepada orang di sekitar kediamaan pemilik kendaraan tersebut, akan tetapi tidak semua tetangga atau orang yang petugas temukan di lapangan mau memberikan informasi kepada petugas mengenai wajib pajak/pemilik kendaraan yang dimaksud.

2. Sarana dan Prasarana. Karena tidak semua pemilik kendaraan bisa membayar pajak kendaraan pada jam kerja Kantor Bersama Samsat Minahasa Utara dikarenakan ada pemilik kendaraan yang bekerja pada jam yang sama.

3. Kendala dari pihak SAMSAT. Pada saat melakukan pelayanan terhadap wajib pajak terkadang terjadi salah penetapan atau salah input data sehingga dapat mengganggu jalannya mekanisme pemungutan pajak kendaraan bermotor yang 
membuat wajib pajak menunggu agar data penetapan atau salah input data diperbaiki.

4. Faktor Masyarakat Sebagai Wajib Pajak. Masih kurangnya pemahaman wajib pajak terhadap penerapan tarif pajak progresif pada kendaraan bermotor.

\section{Dampak Berlakunya Pajak Progresif Kendaraan Bermotor}

Pelaksanaan kenaikan tarif pajak kendaraan bermotor berdampak pada masyarakat dan pemerintah. Dampak positif bagi masyarakat diberlakukannya kenaikan tarif pajak kendaraan bermotor diantaranya mengurangi tingkat kepemilikan kendaraan. Sedangkan dampak positif bagi pemerintah dengan adanya kenaikan tarif pajak kendaraan bermotor yaitu meningkatnya pendapatan asli daerah dalam hal pajak daerah khususnya pajak kendaraan bermotor. Dampak negatif dilakukan oleh masyarakat yaitu masyarakat yang menjadi penguasa kendaraan melakukan perlawanan aktif yakni tax avoidance, dengan semakin berkembangnya ilmu pengetahuan saat ini berdampak juga pada masyarakat. Dengan meningkatnya pengetahuan dan intelektual masyarakat sehingga masyarakat mampu berpikir untuk mengelabuhi aturan yang ada, masyarakat mampu memanfaatkan celah dari suatu peraturan yang ada agar dapat meringankan beban pajak yang harus dibayarkan oleh seorang wajib pajak, hal ini dilakukan agar supaya pemilik kendaraan tidak harus membayar pajak kendaraan dengan tarif yang lebih tinggi.

\section{KESIMPULAN DAN SARAN}

\subsection{Kesimpulan}

Setelah melihat hasil yang diperoleh pada Badan Pengelola Pajak dan Retribusi

Daerah UPTB Minahasa Utara, maka penulis menarik kesimpulan sebagai berikut:

1. Impelemtasi pajak progresif terhadap kendaraan bermotor di Kabupaten Minahasa Utara sudah dilaksanakan berdasarkan dengan aturan yang ada dan wajib pajak/pemilik kendaraan telah membayar PKB sesuai dengan tarif yang berlaku.

2. Implementasi tarif pajak progresif pada kendaraan bermotor diatur dalam Kebijakan Daerah Sulawesi Utara Nomor 7 Tahun 2011 tentang Pajak Daerah. Pajak progresif dikenakan untuk kepemilkan kendaraan pribadi lebih dari satu dengan nama dan alamat yang sama yang penentuan urutannya didasarkan pada tahun tertua kendaraan.

3. Implementasi pajak progresif di Kabupaten Minahasa Utara telah menggunakan sistem komputerisasi yang terintegrasi di mana setiap data wajib pajak yang memiliki kendaraan akan tercatat di dalam database.

4. Belum adanya peraturan yang mengatur secara spesifik mengenai pajak progresif kendaraan bermotor sehingga wajib pajak cenderung melakukan perlawanan aktif yakni tax avoidance.

5. Adanya faktor penghambat dalam implementasi pajak progresif yaitu, faktor petugas yang melakukan pendataan karena sering kali pemilik kendaraan tidak ada di tempat, faktor sarana dan prasarana karena tidak semua wajib pajak dapat membayar pada saat jam kerja kantor SAMSAT selain itu faktor jarak yang jauh, faktor dari SAMSAT yakni terjadi salah penetapan, dan faktor masyarakat yang masih kurang mengetahui dengan tarif pajak progresif.

\subsection{Saran}

Berdasarkan hasil penelitian dan pembahasan serta kesimpulan tersebut, maka penulis memberikan saran antara lain :

1. Petugas melakukan survei secara berkala untuk mengetahui data pembaruan kendaraan wajib pajak khususnya kendaraan yang tidak dikuasai lagi oleh wajib pajak. 
2. Dengan semakin meningkatnya penerimaan pajak kendaraan bermotor perlu diimbangi dengan fasilitas maupun kualitas pelayanan dalam pembayaran pajak yang ada di UPTB Minahasa Utara, agar wajib pajak merasa puas dengan pelayanan yang ada.

3. Untuk mempermudah wajib pajak membayar pajak kendaraan bermotor BP2RD dapat bekerja sama dengan alfa/indomart dalam hal sistem pembayaran pajak kendaraan.

\section{DAFTAR PUSTAKA}

Dunggio, J, A., Elim, I., dan Mawikere, L. 2017. Analisis Penerapan Peraturan Pemerintah Nomor 46 Tahun 2013 Terhadap Pertumbuhan Jumlah Wajb Pajak Dam Penerimaan PPH Pasal 4 Ayat (2). Jurnal Riset Akuntansi Going Concern Vol. 12. No. 2. Universitas Sam Ratulangi.

Korengkeng, R., Karamoy, H., dan Pontoh, W. 2017. Analisis Potensi, Efektivitas, Efisiensi, Dan Kontribusi Pajak Reklame Terhadap Penerimaan Pajak Daerah Di Kabupaten Minahasa Utara. Jurnal Riset Akuntansi Going Concern Vol. 12. No. 1. Universitas Sam Ratulangi.

Londorang, I., Sabijono, H., dan Walandouw, S. 2014. Penerapan Tax Planning Pajak Pertambahan Nilai Terhutang Pada UD. Leonel. Jurnal EMBA, Vol.2 No,2. ISSN : 2303-1174.

Mardiasmo. 2018. Perpajakan Edisi Terbaru. CV. Andi Offsest. Yogyakarta.

Moningka, Novita. 2017. Analisis Pengenaan Tarif Pajak Progresif Pada Kendaraan

Bermotor Berdasarkan The Four Maxims Di Kabupaten Minahasa. Skripsi. Universitas Sam Ratulangi. Manado

Nuzul. 2015. Analisis Penerapan Pajak Progresif Kendaraan Bermotor Dalam Rangka Meningkatkan Pendapatan Asli Daerah Pada Kantor Sistem Administrasi Manunggal

Satu Atap (SAMSAT) Medan Selatan. Skripsi. Universitas Sumatera Utara. Medan

Peraturan Daerah Provinsi Sulawesi Utara. Nomor 7 Tahun 2011 tentang Pajak Daerah.

Pontoh, Winston. 2013. Akuntansi Konsep dan Aplikasi. Halaman Moeka Publishing. Jakarta Barat.

Resmi, Siti. 2014. Perpajakan Teori dan Kasus Edisi 4. Salemba Empat. Jakarta

Sarundayang, M., Karamoy, H., dan Lambey, R. 2018. Analisis Potensi Dan Efektivitas Penerimaan Pajak Reklame Di Kota Manado. Jurnal Riset Akuntansi Going Concern Vol. 13. No. 2. Universitas Sam Ratulangi.

Sujarweni, V. Wiratna. 2014. Metodologi Penelitian. Pustaka Baru, Yogyakarta. Suryabrata.,2013. Metodologi Penelitian, Jakarta, PT. Raja Grafindo Persada. Undang-Undang Republik Indonesia Nomor 28 Tahun 2009. Pajak Daerah dan Retribusi Daerah. Lembaran Negara Republik Indonesia Tahun 2009. Jakarta 